\title{
Health Related Quality of Life of Pregnant Women attending Antenatal Clinic of a Tertiary Level Hospital in Kathmandu
}

\author{
*Radha Paudel ${ }^{1}$, Anisha Deuja² \\ Author Info: \\ ${ }^{1}$ Associate Professor, Nepalese \\ Army Institution of Health \\ Sciences (NAIHS), College of \\ Nursing, Kathmandu, Nepal \\ ${ }^{2}$ Star Hospital, Lalitpur, Nepal
}

\section{*Corresponding Author:}

Radha Paudel;

Email: radha2739@gmail.com

\section{ABSTRACT}

Background: Pregnancy is a normal physiological process; the major changes at that period are related to the direct impact on health-related quality of life. The main objective of the study was to assess the healthrelated quality of life of pregnant women.

Methods: A descriptive cross-sectional study design was used among 106 pregnant women. A non-probability purposive sampling technique was used. Data were collected from 23 August 2019, to 31 August 2019. A semi-structured interview schedule was used for data collection. Data were analyzed by using descriptive statistical methods such as frequency, percentage, mean, standard deviation, and inferential statistics such as Chi-square test and Fischer's exact test was used to associate selected socio-demographic and obstetric characteristics with the level of quality of life. A p value less than 0.05 was used for statistical significance.

Result: The study showed that the respondent's level of health related quality of life was highest in the psychological domain 102 (96.2\%) and the lowest level $15(14.2 \%)$ was found in the physical domain. There was a significant association of physical domain in health related quality of life with the age of pregnant women ( $p-0.003)$ while the type of family, parity, mode of delivery, and duration of pregnancy was not associated with the physical, psychological, and social domain at $p<0.05$.

Conclusion: The health related quality of life of pregnant women, in general, was good. The physical domain was most affected than the psychological and social domain. The level of health related quality of life of the pregnant women in the physical domain is associated with the age of pregnant women. Improving the quality of life of pregnant women requires better identification of their difficulties and guides them from midwives since early pregnancy whenever possible.

Keywords: antenatal clinic; health-related quality of life; pregnant women

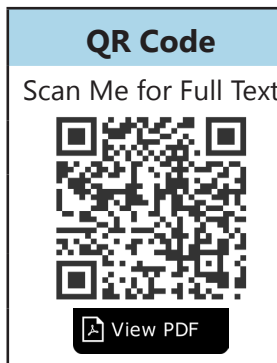
Article Info
Received: 5 November 2020;
Accepted: 27 February 2021;
Published Online: 27 February 2021 How to cite this article in Vancouver Style?
Paudel R, Deuja A. Health related Quality of Life of Pregnant Women attending Antenatal Clinic of a Tertiary Level Hospital in Kathmandu. Europasian J Med Sci. 2021; 3(1): 47-52. https://doi.org/10.46405/ejms.v3i1.223
Disclaimer
Conflict of Interest: None Declared;
Source of Support: Nil
Copyright (C) 2021 by author(s). This work is licensed under the terms and condition of Creative Commons Attribution International License 4.0@ (http://creativecommons.org/licenses/by/4.0/) which permits unrestricted use, distribution, and reproduction in any medium, provided the original work is properly cited. This is an open access publication, and can be downloaded freely from the website of the Journal: www.europasianjournals.org. The Journal as well as publisher remain neutral with regards to any jurisdictional claims in any published articles, its contents and the institutional affiliations of the authors. The Europasian Journal of Medical Sciences (EJMS) (www.europasianjournals.org) is an official Journal of Nirvana Psychosocial Care Center \& Ressearch Institute (www.nirvanapscc.com). 


\section{INTRODUCTION}

Throughout conception, the pregnant woman undertakes major anatomical and physiological changes to foster and accommodate the growing fetus. These changes begin after conception and affect every system in the body. ${ }^{1}$ Pregnancy is a physiological phenomenon; during this period requiring serious bio-psycho-social regulation for women and families. Physical limitations, systemic and hormonal changes cause alterations in pregnancy according to trimesters wise, as a result the pregnant lady also experiences stress, anxieties, and fear at that time about her, the health of the baby, and fear of childbirth. ${ }^{2}$

During pregnancy, physiological and psychosocial changes can influence the organs and certain hormones cause various symptoms that may affect the quality of life. ${ }^{3}$ Lack of strong social, family, and spouse support at that time, stress, and anxieties may develop and generally deprived Health-related Quality of Life (HRQOL) during pregnancy leads to adverse pregnancy outcomes for both the mother and the baby. ${ }^{4}$ In both studies conducted in England and Sweden, the prevalence of stress during pregnancy was reported $33-37 \%$ and $5-7 \%$ respectively, and stress during pregnancy may arise low HRQOL. ${ }^{5} \mathrm{~A}$ study informed that nausea, vomiting, and fatigue in early pregnancy impact on health-related HRQOL of pregnant women. ${ }^{6}$ Overall, Nepal has made substantial progress in improving maternal health care access and utilization however, disparities remain according to women's socioeconomic status, education level, and place of residence, additionally, efforts are needed to improve the quality of maternal health care to end preventable maternal deaths. ${ }^{7}$

HRQOL of pregnant women is not improving yet in developing countries and approximately 800 women die each day from preventable causes related to pregnancy and childbirth where nearly all of these deaths $99 \%$ occur in low-resource settings countries. ${ }^{8}$

Assessing the HRQOL is important in terms of timely preventive measures during pregnancy and should lead to an increase in the quality of care for pregnant women and their well-being, with emphasis on the health of pregnant women. Information on factors influencing the quality of life of women during pregnancy can be useful to promote the HRQOL of pregnant women. However, no study is known to be carried out in Nepal on the HRQOL of pregnant women. Hence, this study aimed to assess HRQOL among pregnant women.

\section{MATERIALS AND METHODS}

A descriptive cross-sectional study design was conducted to assess the HRQOL among pregnant women. A purposive sampling technique was used to select a sample. The study site was Shree Birendra Hospital (SBH) of Chhauni. Data were collected from 23 August 2019, to 31 August 2019. The sample size was calculated using a Cochrane's formula for infinite population $\mathrm{n}=\mathrm{Z}^{2} \mathrm{pq} / \mathrm{d}^{2}$ whereas, $\mathrm{z}=1.96$ ( $5 \%$ level of significance), $p=50(0.5 \%), d=$ allowable error (5\%). The calculated sample size was 96 . Then after $10 \%$ (10) of the calculated sample size was added for possible non-response. The total sample size was 106 pregnant women who were attending the antenatal clinic of SBH. It is a tertiary hospital. Hence, SBH was select for study. All the pregnant women were considered as a study population. Pregnant women of any ages, any trimester, and any parity but who were willing to participate in the study were included in the study and women who had major pregnancy-related disorders like, toxemia of pregnancy, diabetes, anemia, cardiac disease, tuberculosis, etc. were excluded. Data were collected from the interview schedule.

HRQOL measuring scale was adopted from Standardized QOL-GRAV questionnaire, focused on the assessment of the quality of life of pregnant women. ${ }^{9}$ The scale of standardized QOL-GRAV was available in online access. It includes 12 items of the physical domain, 6 items of the psychological domain, and 4 items of the social domain. After pretesting, it was slightly modified on items 3 and 17 of the physical domain, 21 and 22 of the psychological domain. The data were entered and then analyzed in SPSS. The frequencies, percentage, mean, standard deviation, and range were used as a part of descriptive statistics; the Chi-square test and Fischer's exact test was used to associate selected socio-demographic and obstetric characteristics with the level of quality of life. The p-value of less than 0.05 was used for statistical significance.

The ethical approval was taken from the Institutional Review Committee from the Nepalese Army Institute of Health Sciences and permission was obtained from the SBH. Verbal consent was taken from each pregnant woman. The purpose and objectives of the study were explained to the participants. The participant was informed about their right to refuse or to withdraw at any time during the study.

\section{RESULTS}

A total of 106 respondents were involved in this study. Regarding the socio-demographic and 
obstetric information, the mean age was $26.67 \pm$ 3.672 years. The age range of the respondents was 16-44 years. Three-fifth (59.4\%) of them was from a joint family. All (100\%) of them could read and write. The majority (31.1\%) of the respondents had completed graduation. Three-fifth (59.4\%) of them was primipara. All (100\%) of the respondents were suffered from nausea and vomiting since early pregnancy. Three-fourth (75\%) of the respondents had an unplanned current pregnancy.

Regarding the different domains of HRQOL, the respondent's level of HRQOL was highest in the psychological domain (96.2\%) and the lowest level $(14.2 \%)$ was found in the physical domain. Like as

Table 1: Respondent's Level of HRQOL in the Physical, Psychological and Social Domain

\begin{tabular}{|c|c|c|c|c|c|c|}
\hline \multicolumn{3}{|l|}{ Characteristics } & \multicolumn{4}{|c|}{ Level of HRQOL } \\
\hline & & & \multicolumn{2}{|c|}{ Low } & \multicolumn{2}{|c|}{ High } \\
\hline & & & $\mathrm{N}$ & $\%$ & $\mathrm{~N}$ & $\%$ \\
\hline \multicolumn{3}{|l|}{ Physical domain } & 15 & 14.2 & 91 & 85.8 \\
\hline \multicolumn{3}{|c|}{ Psychological domain } & 4 & 3.8 & 102 & 96.2 \\
\hline \multicolumn{3}{|c|}{ Social domain } & 5 & 4.7 & 101 & 95.3 \\
\hline Overall HRQOL & $\begin{array}{l}\text { Very poor } \\
\text { f (\%) }\end{array}$ & $\begin{array}{l}\text { Poor } \\
\mathrm{f}(\%)\end{array}$ & $\begin{array}{l}\text { Neither poor nor } \\
\text { good } \mathrm{f}(\%)\end{array}$ & Good f (\%) & $\begin{array}{c}\text { Very good } \\
\mathrm{f}(\%)\end{array}$ & $\begin{array}{l}\text { Mean +/- } \\
\text { S.D }\end{array}$ \\
\hline HRQOL & 0 & 0 & $9(8.5)$ & $97(91.5)$ & 0 & $3.92+/-3.92$ \\
\hline
\end{tabular}

Table 2: HRQOL in Physical, Psychological and Social Domain of the Respondents

\begin{tabular}{|c|c|c|c|c|c|c|c|}
\hline Statement & $\begin{array}{l}\text { Not at all } \\
f(\%)\end{array}$ & $\begin{array}{l}\text { Little } \\
\text { f (\%) }\end{array}$ & $\begin{array}{l}\text { Moderate } \\
\text { f (\%) }\end{array}$ & $\begin{array}{l}\text { Very much } \\
\quad f(\%)\end{array}$ & $\begin{array}{l}\text { Extreme } \\
f(\%)\end{array}$ & Mean & S.D \\
\hline \multicolumn{8}{|l|}{ Physical Domain } \\
\hline Physical pain & $58(54.7)$ & $25(23.6)$ & $22(20.8)$ & $1(0.90)$ & 0 & 1.68 & 0.834 \\
\hline Need for medical treatment & $106(100)$ & 0 & 0 & 0 & 0 & 1.00 & 0.000 \\
\hline Feeling safety in daily life & 0 & $8(7.5)$ & $45(42.5)$ & $22(20.8)$ & $31(29.2)$ & 3.72 & 0.974 \\
\hline $\begin{array}{l}\text { Physical environment to be } \\
\text { healthy }\end{array}$ & $8(7.5)$ & $14(13.2)$ & $41(38.7)$ & $9(8.5)$ & $34(32.1)$ & 3.44 & 1.273 \\
\hline Energy for everyday life & 0 & $8(7.5)$ & $54(50.9)$ & $32(30.2)$ & $12(11.3)$ & 3.45 & 0.794 \\
\hline Money to meet needs & 0 & 0 & $69(65.1)$ & $9(8.5)$ & $28(26.4)$ & 3.61 & 0.879 \\
\hline Information that need daily life & 0 & 0 & $32(30.2)$ & $33(31.1)$ & $41(38.7)$ & 4.08 & 0.829 \\
\hline Leisure time for extra activities & 0 & $25(23.6)$ & $22(20.8)$ & $11(10.4)$ & $48(45.3)$ & 3.77 & 1.252 \\
\hline Ability to get around & 0 & 0 & $13(12.3)$ & $20(18.9)$ & $73(68.9)$ & 4.57 & 0.704 \\
\hline Sleep & $4(3.8)$ & $23(21.7)$ & $28(26.4)$ & $26(24.5)$ & $25(23.6)$ & 3.42 & 1.179 \\
\hline Ability to perform daily activities & 0 & 0 & $52(49.1)$ & $23(21.7)$ & $31(29.2)$ & 3.80 & 0.867 \\
\hline Capacity for work & 0 & 0 & $55(51.9)$ & $22(20.8)$ & $29(27.4)$ & 3.75 & 0.860 \\
\hline \multicolumn{8}{|l|}{ Psychological Domain } \\
\hline Enjoy the life & 0 & 0 & $77(72.6)$ & $8(7.5)$ & 21(19.8) & 3.47 & 0.807 \\
\hline Feeling life to be meaningful & 0 & 0 & $69(65.1)$ & $25(23.6)$ & 12(11.3) & 3.46 & 0.692 \\
\hline Able to concentrate & 0 & $3(2.8)$ & $34(32.1)$ & $23(21.7)$ & $46(43.4)$ & 4.06 & 0.934 \\
\hline Accept bodily appearance & 0 & 0 & $27(25.5)$ & $23(21.7)$ & $56(52.8)$ & 4.27 & 0.846 \\
\hline Satisfied with own self & 0 & 0 & $35(33.0)$ & $31(29.2)$ & $40(37.7)$ & 4.05 & 0.844 \\
\hline \multicolumn{8}{|l|}{ Social Domain } \\
\hline Personal relationship & 0 & 0 & $27(25.5)$ & $27(25.5)$ & $52(49.1)$ & 4.24 & 0.834 \\
\hline Relation with husband & 0 & 0 & $20(18.90)$ & $13(12.3)$ & $73(68.9)$ & 4.50 & 0.796 \\
\hline Support get from family & 0 & $9(8.5)$ & $25(23.6)$ & $29(27.4)$ & $43(40.6)$ & 4.00 & 0.995 \\
\hline Condition with living places & $4(3.8)$ & $8(7.5)$ & $50(47.2)$ & $15(14.2)$ & $29(27.4)$ & 3.54 & 1.088 \\
\hline
\end{tabular}


Table 3: Association of Socio-demographic and Obstetric Characteristics with Physical, Psychological and Social Domain of HRQOL

Characteristics

\begin{tabular}{cccc}
\hline \multicolumn{4}{c}{ Level of HRQOL } \\
\hline \multicolumn{3}{c}{ Low } & \multicolumn{3}{c}{ High } \\
\hline F & $\%$ & f & $\%$
\end{tabular}

Chi- $\quad$ p-value Square

Physical Domain

Age

$$
\begin{aligned}
& <30 \text { years } \\
& 30+\text { years }
\end{aligned}
$$

$7 \quad 8.3 \quad 77$

$8 \quad 36.4 \quad 14$

91.7

11.275

$0.003^{\text {a* }}$

Type of Family

Nuclear

Joint family

Parity

Primipara

Multipara

Duration of Pregnancy

First trimester

Second trimester

Psychological Domain

Age

$<30$ years

$30+$ years

Type of family

Nuclear
Joint family
Parity

Parity

Primipara

Multipara

$\begin{array}{lll}5 & 11.6 \quad 38\end{array}$

$\begin{array}{lll}10 & 15.9 & 53\end{array}$

$\begin{array}{lll}10 & 15.9 & 53\end{array}$

$\begin{array}{lll}5 & 11.6 & 38\end{array}$

84.1

0.379

$0.585^{\mathrm{a}}$

88.4

$\begin{array}{lll}0 & 0.0 & 1\end{array}$

100.0

$>0.999^{\mathrm{b}}$

15

$12.3 \quad 90$

87.7

Duration of pregnancy

First trimester

Second and third trimester

Social Domain

Age

$$
\begin{aligned}
& <30 \text { years } \\
& 30+\text { years }
\end{aligned}
$$

\section{8}

80

95.2

$0.578^{\mathrm{b}}$

$0 \quad 0.0$

22

100.0

$\begin{array}{llll}0 & 0.0 & 43 & 100.0 \\ 4 & 6.3 & 59 & 93.7\end{array}$

4

6.3

59

93.7

$0.145^{b}$

$0 \quad 0.0$

43

100.0

Type of Family

Nuclear

Joint or Extended

$\begin{array}{lll}0 & 0.0 & 1\end{array}$

100.0

$>0.999^{\mathrm{b}}$

4

$4.9 \quad 101$

95.1

Parity

Primipara

Multipara

Duration of Pregnancy

$<3$ months

$>3$ months

$$
6.0
$$

79

94.0

$0.581^{\mathrm{b}}$

0.0

22

100.0

$0 \quad 0.0$

43

100.0

$0.079^{\mathrm{b}}$

$\begin{array}{llll}5 & 7.9 & 58 & 92.1\end{array}$

5

$\begin{array}{ll}7.9 & 58\end{array}$

92.1

$0.079^{b}$

$\begin{array}{llll}0 & 0.0 & 43 & 100.0\end{array}$

$\begin{array}{lll}0 & 0.0 & 1\end{array}$

100.0

$>0.999^{b}$ 
vast majority (91.5\%) of the respondents had good HRQOL (Table 1).

Regarding the physical domain, more than half of the respondents $(54.7 \%)$ reacted that they had no physical pain at all. Nearly two-fifth (38.7\%) of the respondents felt the physical environment was healthy in moderately amount. Half (50.9\%) of the respondents had a moderate amount of energy for everyday life. Three- fifth (65.1\%) had a moderate amount of money to meet needs. Nearly half $(45.3 \%)$ of them had enough leisure time for extra activities. More than two-fifth (26.4\%) of the respondents responded neutrally to sleep. Regarding the psychological domain, three-fourth $(72.6 \%)$ of the respondents had moderately enjoyed their life. Two-fifth (43.4\%) of the respondents were able to concentrate on an extreme amount. Half (52.8\%) of the respondents were accepted bodily appearance in an extreme amount. Similarly, nearly two-fifth $(37.7 \%)$ of them were very satisfied with their health. Like as, half (49.1\%) had seldom negative feelings. Regarding the social domain, half (49.1\%) of the respondents were very satisfied with a personal relationship, and more than three-fifth (68.9) were very satisfied with a relation with a husband. Twofifth $(40.6 \%)$ of the respondents had support from family in an extreme amount. Likewise, half (47.2\%) of them had a moderate type of living place (Table 2). There was a statistically significant association of the physical domain in HRQOL with the age $(p=0.003)$ (Table 3).

\section{DISCUSSION}

The current study showed that $100 \%$ of the respondents were suffered from nausea and vomiting. This finding is inconsistent with the study conducted in Brazil where as $78.5 \%$ reported nausea and vomiting in pregnancy. The presence of nausea and vomiting were significantly associated with lower quality of life of pregnant women. ${ }^{10}$ Similarly, present study showed that three-fourth (75\%) of the women had an unplanned current pregnancy. This finding was supported by the study conducted in Brazil which showed that pregnant women who were an unplanned pregnancy had higher level of perceived stress which is associated with lower quality of life of pregnant women. ${ }^{10}$

This study showed that the mean age of pregnant women was 26.6 years, and three-fourth (75\%) of the pregnant women had an unplanned current pregnancy. The findings of this study are similar to another study where the mean age was 27.2 years; women with an unplanned pregnancy had lower physical HRQOL than women reporting pregnancies that were planned. ${ }^{11}$

The current study revealed that HRQOL was highest in the psychological domain (96.2\%) and the lowest $(14.2 \%)$ was found in the physical domain. Some findings of another study are inconsistent with present study that reported the physical domain of HRQOL decreased and the mental domain was constant during pregnancy. ${ }^{11}$ Like as some findings of that study are similar to the current study. That study reported leading factors associated with better HRQOL were maternal age and primiparity.

The present study revealed that parity (p-0.269) had no significant effects on the HRQOL of pregnancy. The finding of the study is contradicts with the study conducted in Jordan where only parity (p-0.01) had a significant effect on the HRQOL. ${ }^{13}$ High-parity women had lower HRQOL scores than low-parity women. This disparity between studies might be due to differences in the study setting, sample size, and also level of education of pregnant women. The another study was inconsistent with present study that reported no statistically significant differences in the quality of life in relation to age, parity and period of pregnancy. ${ }^{14}$

The current study depicted that high support from the family was two-fifth (40.6\%), a good relationship with the husband was more than three-fifth (68.9\%). The findings of the study are supported by the study conducted in Jordan where the participants reported high social support, specifically from their families and significant others had high HRQOL during pregnancy. ${ }^{13}$

The present study revealed that the physical domain $(33.59 \pm 0.38)$ was affected more than the psychological domain $(35.42 \pm 0.37)$. The finding of the study is contradicts the study in Columbia where the physical domain was $25 \pm 4$ and the psychological domain was $18 \pm 5$ which might be due to a moderate amount of capacity for work and sleep problems. ${ }^{15}$

The results of this study can be used as a basis for designing appropriate interventions to enhance the lifestyle and subsequently quality of life of pregnant women by policymakers and health-care providers, especially for the health of pregnant women. It is also helpful to provide staff with the necessary training to better justify mothers with the benefits of healthpromoting behavior.

The limitation of the present study was the first, second and third trimesters of pregnancy were taken for the study. Therefore, it is suggested to examine the health related quality of life in the first trimester of pregnancy when hormonal changes, especially 
begin of pregnancy symptoms.

\section{CONCLUSION}

In conclusion, the total quality of life during pregnancy was good. Women had good psychological and social domains rather than the physical domain. However, the age of women significantly affects the quality of life during pregnancy. Improving the quality of life of pregnant women requires better identification of their difficulties and guides them from midwives since early pregnancy whenever possible.

Acknowledge: The researcher would like to acknowledge all the pregnant women involved in the study.

\section{REFERENCES}

1. Soma-Pillay $\mathrm{P}$, Catherine NP, Tolppanen H, Mebazaa A, Tolppanen H, Mebazaa A. Physiological changes in pregnancy. Cardiovascular journal of Africa. 2016; 27(2):89. [Full Text] [Google Scholar]

2. Daglar G, Bilgic D, Ozkan SA. Determinants of quality of life among pregnant women in the city centre of the Central Anatolia region of Turkey. Nigerian Journal of Clinical Practice. 2020; 23(3):416. [Full Text] [Google Scholar]

3. Kazemi F, Nahidi F, Kariman N. Exploring factors behind pregnant women's quality of life in Iran: a qualitative study. Electronic physician. 2017; 9(12):5991. [Full Text] [Google Scholar]

4. Shishehgar S, Mahmoodi A, Dolatian M, Mahmoodi Z, Bakhtiary M, Majd HA. The relationship of social support and quality of life with the level of stress in pregnant women using the PATH model. Iranian Red Crescent Medical Journal. 2013; 15(7):560. [Full Text] [Google Scholar]

5. Senturk V, Abas M, Berksun O, Stewart R. Social support and antenatal depression in extended and nuclear family environments in Turkey: a cross-sectional survey. BMC psychiatry. 2011; 11(1):48. [Full Text] [Google Scholar]

6. Bai G, Korfage IJ, Groen EH, Jaddoe VW, Mautner E, Raat H. Associations between nausea, vomiting, fatigue and health-related quality of life of women in early pregnancy: the generation R study. PloS one. 2016; 11(11):e0166133. [Google Scholar]

7. Banstola A. The Current State of Maternal Health in Nepal. 2017. [Full Text]

8. Bhusal C, Bhattarai S, Bhaskar RK. Maternal health in Nepal progress, challenges and opportunities. Int J Med Health Res. 2015; 1(3):68-73. [Google Scholar]

9. Vachkova E, Jezek S, Mares J, Moravcova M. The evaluation of the psychometric properties of a specific quality of life questionnaire for physiological pregnancy. Health and quality of life outcomes. 2013; 11(1):214. [Google Scholar]

10. Calou CG, Pinheiro AK, Castro RC, Oliveira MF, Aquino PD, Antezana FJ. Health related quality of life of pregnant women and associated factors: An integrative review. Health.2014; 6(18):23752387. [Full Text] [Google Scholar]

11. Gariepy A, Lundsberg LS, Vilardo N, Stanwood N, Yonkers K, Schwarz EB. Pregnancy context and women's health-related quality of life. Contraception. 2017; 95(5):491-9. [Google Scholar]

12. Lagadec N, Steinecker M, Kapassi A, Magnier AM, Chastang J, Robert S, Gaouaou N, Ibanez G. Factors influencing the quality of life of pregnant women: a systematic review. BMC pregnancy and childbirth. 2018; 18(1):455. [Full Text]

13. Alzboon G, Vural G. Factors influencing the quality of life of healthy pregnant women in North Jordan. Medicina. 2019;55(6):278. [Full Text] [ G o o g l e Scholar]

14. Mazúchová L, Kelčíková S, Dubovická Z. Measuring women's quality of life during pregnancy. Kontakt. 2018; 20(1):e31-6. [Google Scholar]

15. Ramírez-Vélez R. Pregnancy and health-related quality of life: A cross sectional study. Colombia Médica. 2011; 42(4):476-481. [Full Text] 